\title{
Buckling Stability Assessment of Plates with Various Boundary Conditions Under Normal and Shear Stresses
}

\author{
Farhad Riahi \\ Department of Civil \\ Engineering \\ Islamic Azad University \\ Mahabad, Iran \\ riahi.farhad@gmail.com
}

\author{
Alaeddin Behravesh \\ Department of Civil \\ Engineering \\ Islamic Azad University \\ Mahabad, Iran \\ behravesh@tabrizu.ac.ir
}

\author{
Mikaeil Yousefzadeh Fard \\ Department of Civil \\ Engineering \\ Islamic Azad University \\ Mahabad, Iran \\ mikaiel@ymail.com
}

\author{
Arasto Armaghani \\ Department of Civil \\ Engineering \\ Islamic Azad University \\ Mahabad, Iran \\ Aarmaghani@yahoo.com
}

\begin{abstract}
In the present paper, the buckling behavior of plates subjected to shear and edge compression is investigated. The effects of the thickness, slenderness ratio and plate aspect ratio are investigated numerically. Effects of boundary conditions and loadings are also studied by considering different types of supports and loading. Finally, the results of numerical methods are compared with the theoretical results. This work mainly investigates the buckling behavior of plates but also the capabilities of program of plate-buckling (PPB) and ABAQUS for performing linear and nonlinear buckling analyses. The results will be useful for engineers designing walls or plates that have to support intermediate floors/loads.
\end{abstract}

Keywords-steel plate; thin plates; buckling; finite element method; boundary condition

\section{INTRODUCTION}

The problem of buckling of a plate subjected to in-plane compressive and shear loading is important in the shipbuilding, thin-walled structures and building industries. The term buckling refers to when a plate loses its stability, which may lead to a sudden and catastrophic failure, such as the complete collapse or breakage of the structure. When compressive loading is present, buckling may become a concern. Buckling is a big problem, particularly in thin-walled structures where the membrane stiffness is much greater than the bending stiffness. An energy method to study the buckling behavior of rectangular plates subjected to in-plane shear load was utilized $[1,2]$. Later, author in [3], considered a uniaxial compressive loading with a parabolic distribution and obtained an energy solution [3, 4]. Authors in [5] have performed elasto-plastic buckling analysis of simply supported plates subjected to uniaxial compression load [5]. Authors in [6, 7], showed that the differential quadrature method can yield accurate buckling loads for rectangular plates under uniformly or non-uniformly distributed edge compressions [6, 7]. The present paper evaluates the buckling load of the plate, which is subjected to uniaxial compression and shear load using finite element method software ABAQUS and (PPB). The analysis is done using Eurocode 3. The buckling load is evaluated by changing parameters such as aspect ratio $\mathrm{a} / \mathrm{b}$, thickness plate $\mathrm{t}$, slenderness ratio $\beta$, slenderness parameter $\lambda$, mesh sizes and boundary conditions. The effects of these parameters are studied on buckling load. The accuracy of the current analysis is validated through comparison studies. Several case studies are then performed in order to gain a better understanding of some uncovered aspects of buckling stability of such thinwalled structures.

\section{PlATE GEOMETRY AND MECHANICAL PROPERTIES}

All the FE models used in this part and their geometrical parameters are declared in Table I. Dimension of the length of the plate (a) are 750, 1500, 2250 and $3000 \mathrm{~mm}$, the width of the plate (b) is $750 \mathrm{~mm}$, therefore the ratio $\mathrm{a} / \mathrm{b}$ for the plate is taken as 1, 2, 3 and 4 respectively Thickness of the plate $(\mathrm{t})$ is taken as 3, 5, 7.5 and $10 \mathrm{~mm}$. Naming Specimens are presented as follows: P-i, plate specimens, as shown in Table I, where (i) number of plate by different aspect ratios. For each boundary condition, four aspect ratios and four thicknesses of the plate and three mesh size are considered and total specimens are 96.

TABLE I. GEOMETRICAL PROPERTIES OF PLATE MODELS

\begin{tabular}{|c|c|c|c|}
\hline $\boldsymbol{\alpha}=\boldsymbol{a} / \boldsymbol{b}$ & Plate Model & $\boldsymbol{a}(\mathbf{m m})$ & $\boldsymbol{b}(\mathbf{m m})$ \\
\hline 1 & P-1 & 750 & 750 \\
\hline 2 & P-2 & 1500 & 750 \\
\hline 3 & P-3 & 2250 & 750 \\
\hline 4 & P-4 & 3000 & 750 \\
\hline
\end{tabular}

\section{A. Boundary Conditions and Load Types}

The type of boundary condition used for the models is simple and clamped. Three different types of load are considered in the FE models, in-plane shear load and uniaxial compression load and combined compression and shear, see Figure 1. As magnitude, in all of the linear buckling analyses, a unit load is applied to the involved edges. In the nonlinear buckling analyses, the load is applied incrementally. 


\section{MODELLING DETAILS AND VALIDATION}

The modulus of elasticity analyses, is set to $210 \mathrm{GPa}$, the Poisson's ratio $v$, is 0.3 and the yield stress of the metal is selected as $355 \mathrm{MPa}$. The introduced dimensionless variables, and parameters: plate in-plane (xy), of length (a) along x-axis, width (b) along $y$-axis and uniform thickness ( $t$ ) along $\mathrm{z}$-axis as shown in Figure1 are considered.

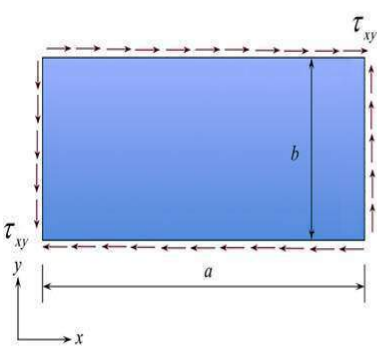

(a) In-plane shear load

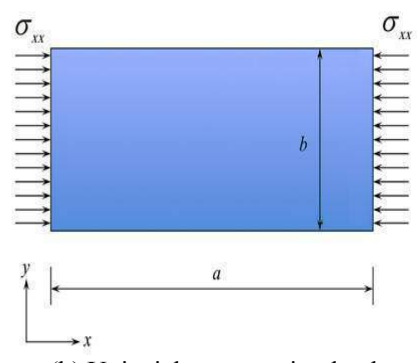

(b) Uniaxial compression load

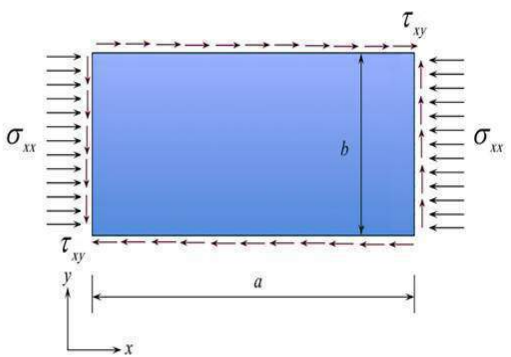

(c) Combined compression and shear loads

Fig. 1. Three types of load are used in the parametric studies

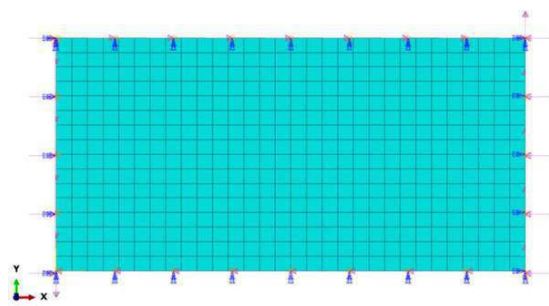

(a) ABAQUS

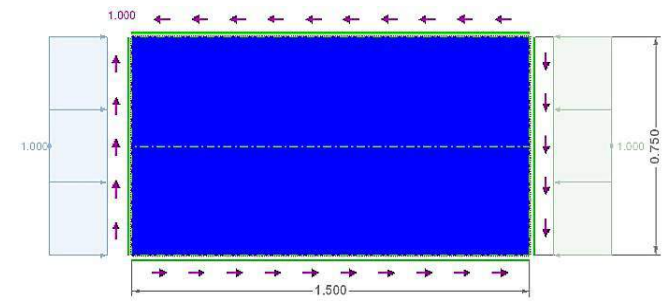

(b) Program of Plate-Buckling (PPB)

Fig. 2. Typical of Combined compression and shear loads

The buckling of thin plate theory is used for calculating the critical buckling load of plates with various geometries, boundary conditions and exposed to loading types such as inplane shear and/or uniaxial compression $[9,10]$. The Program of Plate-Buckling (PPB) is used for every plate buckling analysis according to EN 1993-1-5, the reduced stresses are implemented in plate buckling [11]. In nonlinear buckling analysis, the method for evaluating if a structure buckles or not is always done by using a force versus the out-of-plane displacement. Program of Plate-Buckling and ABAQUS have both their own eight-node shell element formulation implemented $[10,12]$.

\section{A. Details Mesh Size}

The software ABAQUS CAE 2016 [1] was used, with each model finite element defined by eight-node shell element (S8R5) with quadratic base function and reduced integration being selected for modeling the plates. In this study dimensions for the width of the plate for all models are taken $750 \mathrm{~mm}$. three types of mesh are selected based on the width of the plate. Small mesh with 16 elements in the width of the plate, medium mesh with 8 elements in the width of the plate, large mesh with 6 elements in the width of the plate. In this paper the effect of the type of mesh on buckling analysis plates is investigated.

\section{B. Plates with Simple and Clamped Edges}

It is necessary to perform verification and validation for the FEM analysis results to ensure that the loading, buckling strength and acceptance criteria are suitably considered. For numerical comparison of the result of the Program of PlateBuckling and ABAQUS, it is necessary to define of discrepancy parameter (D).

$$
D=\left(\frac{\text { Result }_{F E M}-\text { Result }_{P P B}}{\text { Result }_{P P B}}\right) \times 100
$$

The results of examination of the effect of length/ width of the plate ratio $(\mathrm{a} / \mathrm{b})$ on buckling loads of the plates subjected to external pressure and modeled with clamped boundary conditions for support are presented in Table III. The results of examination of the effect of length/width of the plate ratio $(\mathrm{a} / \mathrm{b})$ on buckling loads of the plates subjected to external pressure and modelled with simple boundary conditions for supports are presented in Table III and Table IV. According to Tables III and IV it can be seen that the convergence between the results of PPB and FEM models is explicit, but in the P1 model is a square plate and with the lowest number of mesh, the results were different. By increasing the aspect ratio and in the rectangular plates, differences between the results lessen. 


\section{RESULTS AND DISCUSSION}

\section{A. General}

The buckling behavior of plates is investigated in this paper for different types of boundary condition, aspect ratios, slenderness parameters, mesh size and plate thickness.

\section{B. Effect of Slenderness Parameter}

Authors in [8] investigated the effect of slenderness parameter on metal plates subjected to in-plane shear load. Slenderness ratio is used to describe the ratio between the width and thickness of the plate while the slenderness parameters also involve the yield stress and Young's modulus of the material;

$$
\begin{aligned}
& \beta=\frac{b}{t} \\
& \lambda=\beta \sqrt{\sigma_{y} / E}
\end{aligned}
$$

Where $\beta$ is the slenderness ratio, $b$ is the shortest side of the plate, $\mathrm{t}$ is the thickness, $\lambda$ is the slenderness parameter, $E$ is the elastic Young's modulus and $\sigma_{\mathrm{y}}$ is the yield stress.

TABLE II. SLENDERNESS RATIO $(\beta)$ AND SLENDERNESS $(\lambda)$ $(\lambda)$

\begin{tabular}{|c|c|c|c|}
\hline $\boldsymbol{b}(\mathbf{m m})$ & $\boldsymbol{t}(\mathbf{m m})$ & $\boldsymbol{\beta}$ & $\boldsymbol{\lambda}$ \\
\hline 750 & 3 & 250 & 10.27 \\
\hline 750 & 5 & 150 & 6.16 \\
\hline 750 & 7.5 & 100 & 4.11 \\
\hline 750 & 10 & 75 & 3.08 \\
\hline
\end{tabular}

Plates can be divided into three groups depending on geometrical dimensions: slender, moderate and stocky. The authors concluded that for slender plates with $\lambda \geq 6$, elastic buckling loads predicted numerically using the Finite Element Method are in total agreement with those obtained from theory. Slender plates buckle at lower loads and bifurcate mainly due to geometrical instability within the elastic limits of the material. Stocky plates, where $\lambda \leq 3$, show a material bifurcation i.e., they buckle in an inelastic way closer to the yield limit implying that a linear buckling analysis approach is not sufficient to catch the buckling behavior. The slender plates show a load carrying capacity up to the ultimate load after the buckling load is reached [8].

\section{Buckling Coefficients}

Buckling coefficients of simply and clamped supported plates are calculated by the Rayleigh-Ritz method. Table V summarizes the buckling coefficients $\mathrm{k}_{\sigma}$ obtained by the PPB and by using ABAQUS. One can clearly see the effect of boundary conditions as well as aspect ratios on buckling loads. Maximum of buckling coefficient $\mathrm{k}_{\sigma}$ for plates with all edges simply and clamped supported subjected to normal stress respectively: $\mathrm{k}_{\sigma}=5.23$ and $\mathrm{k}_{\sigma}=12.41$. This research showed that the actual ultimate carrying capacity was much larger than the critical load. This was most obvious with the slenderer plates. Turning our attention to support conditions and geometric situation of several plates, it could be claimed that by the increase in length to width ratio of the plates, critical stress and buckling coefficient decline.

\begin{tabular}{|c|c|c|c|c|c|c|c|c|c|c|}
\hline \multirow{3}{*}{$\begin{array}{l}\text { Plate } \\
\text { Model }\end{array}$} & \multirow{3}{*}{$\begin{array}{c}\text { Thickness } \\
\text { (mm) }\end{array}$} & \multicolumn{9}{|c|}{ Mesh Size } \\
\hline & & \multicolumn{3}{|c|}{ Small } & \multicolumn{3}{|c|}{ Medium } & \multicolumn{3}{|c|}{ Large } \\
\hline & & $\begin{array}{c}\text { Normal } \\
\text { Stress } \\
\end{array}$ & $\begin{array}{l}\text { Shear } \\
\text { Stress }\end{array}$ & *Combined & $\begin{array}{c}\text { Normal } \\
\text { Stress }\end{array}$ & $\begin{array}{l}\text { Shear } \\
\text { Stress }\end{array}$ & *Combined & $\begin{array}{c}\text { Normal } \\
\text { Stress }\end{array}$ & $\begin{array}{l}\text { Shear } \\
\text { Stress }\end{array}$ & ${ }^{*}$ Combined \\
\hline $\mathrm{P}-1$ & \multirow{4}{*}{3} & 0.37 & 4.68 & 0.25 & 0.57 & 13.37 & 1.42 & 0.82 & 26.77 & 3.11 \\
\hline $\mathrm{P}-2$ & & 0.28 & -3.12 & -0.57 & 0.42 & -3.51 & -0.71 & 0.12 & -6.73 & -1.42 \\
\hline $\mathrm{P}-3$ & & 0.24 & -0.84 & 0.79 & 0.42 & -1.05 & -0.75 & 0.14 & -2.97 & -1.37 \\
\hline $\mathrm{P}-4$ & & 0.23 & -0.49 & -0.77 & 0.40 & -0.66 & -0.78 & 0.08 & -2.19 & -1.56 \\
\hline & & & & & & & & & & \\
\hline P-1 & \multirow{4}{*}{5} & 0.61 & 4.92 & 0.91 & 0.70 & 14.27 & 1.15 & 1.03 & 29.69 & 3.08 \\
\hline $\mathrm{P}-2$ & & 0.46 & -3.01 & -0.72 & 0.57 & -3.22 & -0.67 & 0.56 & -4.74 & -1.6 \\
\hline $\mathrm{P}-3$ & & 0.41 & -0.73 & -0.67 & 0.54 & -0.86 & -0.64 & 0.59 & -1.73 & -1.62 \\
\hline $\mathrm{P}-4$ & & 0.39 & -0.39 & -0.69 & 0.51 & -0.50 & -0.61 & 0.53 & -1.18 & -1.68 \\
\hline & & & & & & & & & & \\
\hline $\mathrm{P}-1$ & \multirow{4}{*}{7.5} & 0.93 & 5.24 & 1.12 & 0.91 & 14.82 & 0.91 & 1.22 & 31.15 & 2.72 \\
\hline $\mathrm{P}-2$ & & 0.71 & -2.85 & -1.4 & 0.78 & -2.99 & -0.88 & 0.84 & -3.85 & -1.91 \\
\hline $\mathrm{P}-3$ & & 0.64 & -0.58 & -1.17 & 0.71 & -0.68 & -0.81 & 0.83 & -1.18 & -1.89 \\
\hline $\mathrm{P}-4$ & & 0.61 & -0.24 & -1.3 & 0.68 & -0.33 & -0.9 & 0.78 & -0.73 & -1.86 \\
\hline $\mathrm{P}-1$ & \multirow{4}{*}{10} & 1.26 & 5.60 & 1.23 & 1.17 & 15.25 & 1.53 & 0.54 & 31.94 & 2.96 \\
\hline $\mathrm{P}-2$ & & 0.97 & -2.66 & -1.4 & 1.01 & -2.78 & -1.7 & 1.08 & -3.38 & -1.24 \\
\hline $\mathrm{P}-3$ & & 0.88 & -0.40 & -1.29 & 0.92 & -0.49 & -1.16 & 1.03 & -0.86 & -1.31 \\
\hline $\mathrm{P}-4$ & & 0.83 & -0.06 & -1.22 & 0.87 & -0.15 & -1.29 & 0.98 & -0.45 & -1.28 \\
\hline
\end{tabular}

TABLE III. DISCREPANCY (\%) BETWEEN PPB AND FEM PREDICTIONS OF CRITICAL BUCKLING STRESS WITH SIMPLY SUPPORTED CONDITIONS (SSSS). 
TABLE IV. DISCREPANCY (\%) BETWEEN PPB AND FEM PREDICTIONS OF CRITICAL BUCKLING STRESS WITH CLAMPED SUPPORTED CONDITIONS(CCCC).

\begin{tabular}{|c|c|c|c|c|c|c|c|c|c|c|}
\hline \multirow{3}{*}{$\begin{array}{l}\text { Plate } \\
\text { Model }\end{array}$} & \multirow{3}{*}{$\begin{array}{c}\text { Thickness } \\
\text { (mm) }\end{array}$} & \multicolumn{9}{|c|}{ Mesh Size } \\
\hline & & \multicolumn{3}{|c|}{ Small } & \multicolumn{3}{|c|}{ Medium } & \multicolumn{3}{|c|}{ Large } \\
\hline & & $\begin{array}{c}\text { Normal } \\
\text { Stress }\end{array}$ & $\begin{array}{l}\text { Shear } \\
\text { Stress }\end{array}$ & *Combined & $\begin{array}{c}\text { Normal } \\
\text { Stress }\end{array}$ & $\begin{array}{l}\text { Shear } \\
\text { Stress }\end{array}$ & *Combined & $\begin{array}{c}\text { Normal } \\
\text { Stress }\end{array}$ & $\begin{array}{l}\text { Shear } \\
\text { Stress }\end{array}$ & *Combined \\
\hline $\mathrm{P}-1$ & \multirow{4}{*}{3} & 0.008 & 0.17 & 0.185 & -0.033 & -2.29 & -1.26 & -0.329 & -15.05 & -6.31 \\
\hline $\mathrm{P}-2$ & & 0.008 & -3.24 & -1.54 & -0.041 & -3.73 & -2.43 & -0.708 & -8.05 & -2.8 \\
\hline $\mathrm{P}-3$ & & 0.008 & -0.95 & 0.9 & -0.041 & -1.25 & -0.95 & -0.757 & -3.91 & -1.64 \\
\hline $\mathrm{P}-4$ & & 0.008 & -0.60 & -0.087 & -0.041 & -0.83 & -1.3 & -0.708 & -2.96 & -0.92 \\
\hline & & & & & & & & & & \\
\hline $\mathrm{P}-1$ & \multirow{4}{*}{5} & 0.024 & 0.23 & 0.42 & 0.006 & -0.88 & 0.95 & -0.110 & -7.01 & -1.30 \\
\hline $\mathrm{P}-2$ & & 0.024 & -3.20 & -2.72 & 0.003 & -3.44 & -2.4 & -0.249 & -5.47 & -2.45 \\
\hline $\mathrm{P}-3$ & & 0.024 & -0.91 & -1.67 & 0.003 & -1.07 & -0.97 & -0.270 & -2.26 & -0.96 \\
\hline $\mathrm{P}-4$ & & 0.024 & -0.57 & -1.09 & 0.003 & -0.70 & -1.05 & -0.249 & -1.64 & -0.94 \\
\hline $\mathrm{P}-1$ & \multirow{4}{*}{7.5} & 0.055 & 0.34 & 1.32 & 0.045 & -0.26 & -0.73 & -0.014 & -3.74 & -1.87 \\
\hline $\mathrm{P}-2$ & & 0.055 & -3.13 & -2.54 & 0.043 & -3.28 & -1.47 & -0.076 & -4.39 & -2.34 \\
\hline $\mathrm{P}-3$ & & 0.055 & -0.85 & -1.5 & 0.042 & -0.96 & -1.11 & -0.087 & -1.62 & -0.82 \\
\hline $\mathrm{P}-4$ & & 0.055 & -0.52 & -1.2 & 0.043 & -0.61 & -1.32 & -0.076 & -1.13 & -0.76 \\
\hline P-1 & \multirow{4}{*}{10} & 0.103 & 0.49 & 0.89 & 0.088 & 0.08 & 0.78 & 0.051 & -2.24 & -1.12 \\
\hline $\mathrm{P}-2$ & & 0.103 & -3.03 & -1.6 & 0.088 & -3.15 & -1.07 & 0.014 & -3.89 & -0.81 \\
\hline $\mathrm{P}-3$ & & 0.103 & -0.77 & -1.44 & 0.088 & -0.86 & -1.03 & 0.014 & -1.32 & -0.87 \\
\hline $\mathrm{P}-4$ & & 0.103 & -0.43 & -1.28 & 0.088 & -0.52 & -0.92 & 0.014 & -0.88 & -0.95 \\
\hline
\end{tabular}

Buckling coefficients $\mathrm{k}_{\tau}$ for plates with all edges simply supported subjected to In-plane shear load, are shown in (4).

$$
k_{\tau}=5.34+\frac{4}{(a / b)^{2}}
$$

As the plate is shortened, the number of local buckles is reduced and the value of buckling coefficients $k_{\tau}$ for a plate simply supported on all four edges is increased from 5.36 for a very long plate to 9.94 for a square plate and for a plate clamped supported on all four edges is increased from 6.23 for a very long plate to 10.75 for a square plate.

TABLE V. BUCKLING COEFFICIENT $k_{\sigma}$ FOR PLATES UNDER UNIAXIALDISTRIBUTED EDGE COMPRESSIONS

\begin{tabular}{|c|c|c|c|c|c|c|c|c|}
\hline \multirow{2}{*}{$\mathbf{a} / \mathbf{b}$} & \multicolumn{2}{|c|}{$\mathbf{1}$} & \multicolumn{2}{|c|}{$\mathbf{2}$} & \multicolumn{2}{|c|}{$\mathbf{3}$} & \multicolumn{2}{|c|}{} \\
\cline { 2 - 9 } & PPB & FEM & PPB & FEM & PPB & FEM & PPB & FEM \\
\hline SSSS & 5.22 & 5.23 & 5.35 & 5.30 & 5.92 & 5.87 & 6.34 & 6.27 \\
\hline CCCC & 12.41 & 12.20 & 10.7 & 10.6 & 10.3 & 10.3 & 9.98 & 9.98 \\
\hline
\end{tabular}

TABLE VI. BUCKLING COEFFICIENT $k_{\tau}$ FOR PLATES UNDER IN-PLANE SHEAR LOAD EDGE

\begin{tabular}{|c|c|c|c|c|c|c|c|c|}
\hline \multirow{2}{*}{$\mathbf{a} / \mathbf{b}$} & \multicolumn{2}{|c|}{$\mathbf{1}$} & \multicolumn{2}{|c|}{ 2 } & \multicolumn{2}{|c|}{ 3 } & \multicolumn{2}{|c|}{ 4 } \\
\cline { 2 - 9 } & PPB & FEM & PPB & FEM & PPB & FEM & PPB & FEM \\
\hline SSSS & 9.94 & 9.03 & 6.34 & 6.21 & 5.78 & 5.57 & 5.59 & 5.36 \\
\hline CCCC & 10.75 & 10.44 & 8.57 & 8.48 & 7.81 & 6.92 & 6.84 & 6.23 \\
\hline
\end{tabular}

The aspect ratio of the plate determines the number of folds or lobes formed at buckling. Considering that $\mathrm{m}$ and $\mathrm{n}$ are the number of half waves in $\mathrm{x}$ and $\mathrm{y}$ directions respectively, for the m-n buckling mode. For the lowest value of critical load, number of half waves along the width of the plate $n$ is one, while the number of half waves formed along the length of the plate is governed by the aspect ratio of the plate. The value of $\mathrm{k}$ depends on the number of half waves $m$ and the aspect ratio, as graphed in Figure 3, shows the plots of the buckling coefficient (k) versus $\mathrm{a} / \mathrm{b}$ for plates.

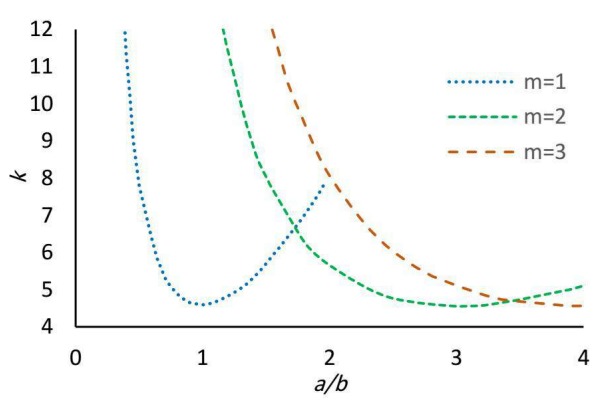

(a) Buckling factor

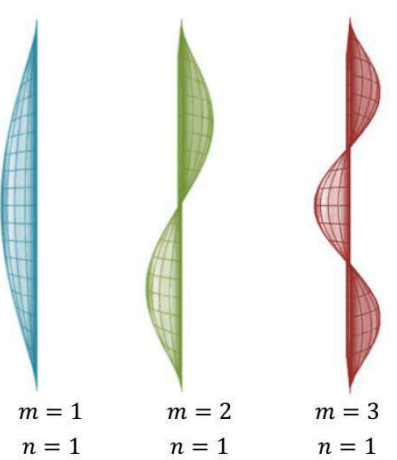

(b) Buckling modes

Fig. 3. Variation of buckling factor with the plate aspect ratio

The value of $\mathrm{k}$ is minimal at the integer values of aspect ratio for which the number of half waves is equal to the aspect ratio. At the aspect ratio of the plate more than the transitional value of $\alpha=a / b$ for $m=1$ to $m=2$, the number of half waves 
which have been formed will change to 2 to maintain the lowest value of $(\mathrm{k})$.

\section{Local Buckling Load}

The local buckling stresses $\left(\sigma_{\mathrm{cr}}\right)$ are obtained from FEM. The axial compression load versus out-of-plane displacement curves were used to obtain the local buckling load with different support condition as shown in Figures 4 5. Bifurcation curve was seen in the local buckling of plates. This lead to gradual out-of-plane displacement even at lower axial compression loads. In Figure 4 and clamped support condition, the maximum and minimum out-of-plane displacement respectively was for plate with thickness of 3 and $10 \mathrm{~mm}$. The highest and lowest values of out-of-displacement were 2 and $1.2 \mathrm{~mm}$. In Figure 5 and simply support condition the maximum and minimum out-of-plane displacement respectively was for plate with a thickness of 3 and $10 \mathrm{~mm}$. The highest and lowest values of out-of-displacement were 2.2 and $1.6 \mathrm{~mm}$. The axial compression load often dropped rapidly after reaching the ultimate strength. This might be due to the assumption of ideal perfect-plastic material behavior in ABAQUS. The first Buckling modes and out-of-plane displacement plates with various aspect ratios are shown in Figure 6.

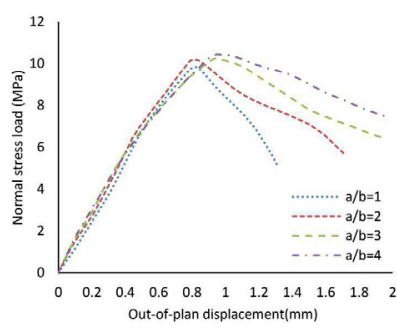

(a) Plate with a thickness of $3 \mathrm{~mm}$

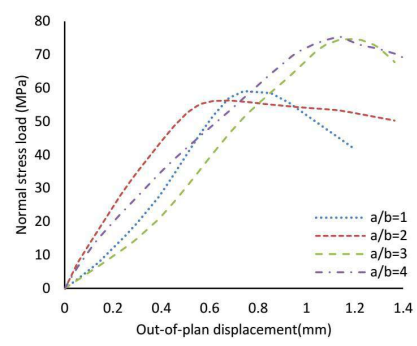

(c) Plate with a thickness of $7.5 \mathrm{~mm}$

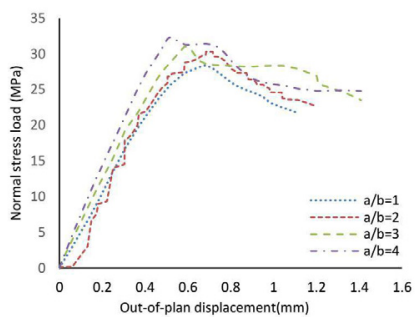

(b) Plate with a thickness of $5 \mathrm{~mm}$

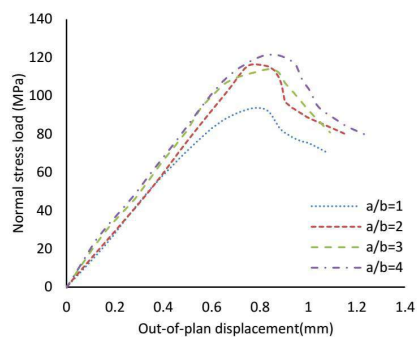

(d) Plate with a thickness of $10 \mathrm{~mm}$

Fig. 4. Plot of normal stress load versus out-of-plane displacement with Support condition: CCCC

\section{E. Interaction Relation Between $\sigma / \sigma_{c r}$ and $\tau / \tau_{c r}$}

For combined loadings the general conditions for failure are expressed by (5):

$$
R_{1}+R_{2}=1
$$

In this equation, $R_{1}=\sigma / \sigma_{c r}$ and $R_{2}=\tau / \tau_{c r}$ could refer to normal and shear stresses are applied to the edges of the plate. Figure 7 shows the interaction relation curves for different aspect ratio between $\sigma / \sigma_{c r}$ and $\tau / \tau_{c r}$ for simply and clamped supported.

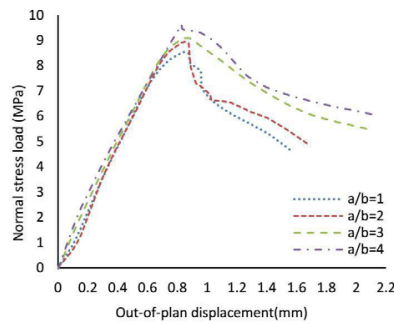

(a) Plate with a thickness of $3 \mathrm{~mm}$

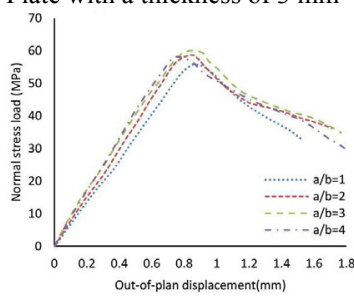

(c) Plate with a thickness of $7.5 \mathrm{~mm}$

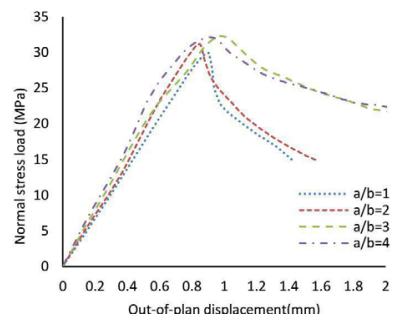

Out-of-plan displacement(mm)

(b) Plate with a thickness of $5 \mathrm{~mm}$

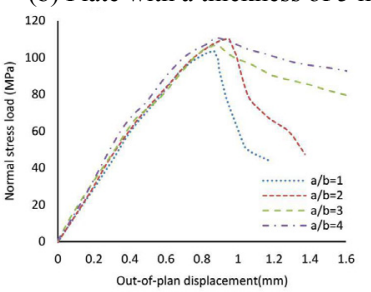

(d) Plate with a thickness of $10 \mathrm{~mm}$
Fig. 5. Plot of normal stress load versus out-of-plane displacement with Support condition: SSSS

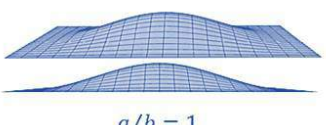

$a / b=1$

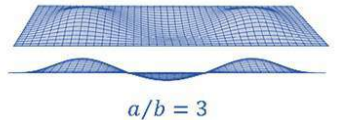

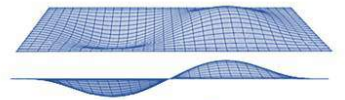

$a / b=2$

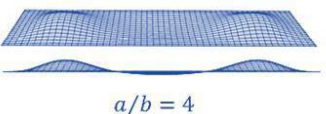

Fig. 6. Buckling modes of plates with out-of-plane displacement and different aspect ratios

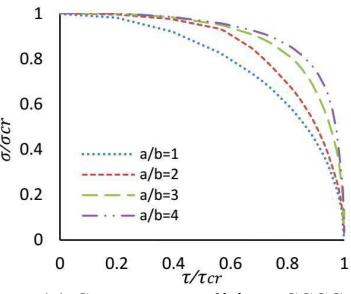

(a) Support condition: SSSS

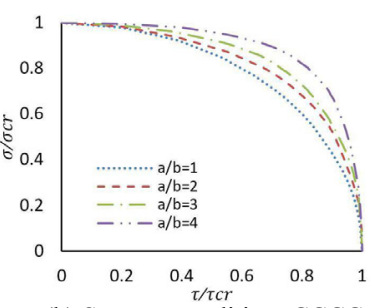

(b) Support condition: $\mathrm{CCCC}$
Fig. 7. Interaction relation between $\sigma / \sigma_{c r}$ and $\tau / \tau_{c r}$

When the aspect ratio $a / b=1$, the interaction relation curves lie slightly below the circular curve. The interaction between compression and shear is therefore significant due to the fact that the aspect ratio $\mathrm{a} / \mathrm{b}=1$ causes twisting buckling mode. As the aspect ratio increases, the interaction relation curves lie further above the circular curve. The interaction relation is therefore less significant.

\section{F. First Eigen Mode for Various Cases of Plates}

This part of paper contains the results that are obtained by the FE models that were presented in the previous part. In the 
paper, some selected contour plots are presented in order to illustrate the buckling modes for various cases of plates. The results for the first Eigen mode (z-displacement magnitude) obtained in the paper where the aim was to perform a mesh convergence study. Figure 8 shows square plates with two types of loads and mesh size and Figure 9, shows rectangular plates for two types of loads and mesh size.

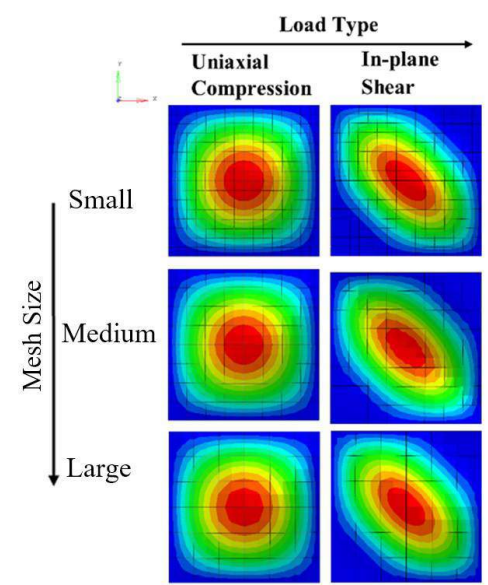

Fig. 8. The first Eigen mode of Square Plate in ABAQUS

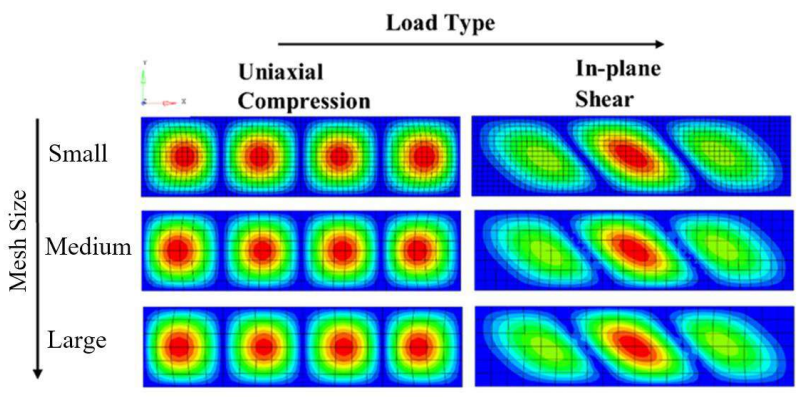

Fig. 9. The first Eigen mode of Rectangular Plate in ABAQUS

\section{CONCLUSION}

Buckling analysis of plates with uniform distributed inplane shear and compressive loadings along edges is investigated. The plate aspect ratio was supposed that varies from 1 to 4 and with several loading states, 96 models were considered. ABAQUS and PLATE-BUCKLING programs were used for modeling and analysis of the considered plate models. The numerical predictions of the two aforementioned programs were compared for verification purposes. The major findings of this research are summarized in the following:

- Fixity of the loading edges can be effective in improving the buckling strength of plates as the aspect ratio gets smaller than unity, while loading edges fixity does not seem to have a considerable effect on the buckling capacity in plates with aspect ratios larger than unity.

- The buckling coefficients decrease when the aspect ratio increases. The decreasing in the buckling coefficients when the aspect ratio $\mathrm{a} / \mathrm{b}=1$ less than the decreasing in the buckling coefficients when the aspect ratio $\mathrm{a} / \mathrm{b}>1$. The decrease in the buckling coefficients in plate with boundary condition (SSSS) is more than the decreasing in the buckling coefficient in plate with boundary condition (CCCC).

- The buckling loads and modes were evaluated numerically as stated above. Eigenvalues were calculated for unit lineload $(1 \mathrm{~N} / \mathrm{mm})$ and then the buckling load in each mode was calculated by multiplying the eigenvalue with the width of the plate.

- Buckling load decreases with the increasing aspect ratio.

- Buckling load increases with the increase in the thickness of the plates.

The main objective of this research is to explore some uncovered aspects of buckling stability of plates by considering the effects of support conditions, aspect ratio, and slenderness ratio, which will consequently result in efficient design of such thin-walled structures.

\section{REFERENCES}

[1] S. P. Timoshenko, Theory of Elastic Stability, McGraw-Hill Book Company, Inc. New York, 1936

[2] M. Stein, J. Neff, Buckling Stresses of Simply Supported Rectangular Flat Plates in Shear, NACA Technical Note, No.1559, 1947

[3] M. B. Benoy, "An energy solution to the buckling of rectangular plates under non-uniform in-plane loading", Aeronautical Journal, Vol. 73, pp. 974-7, 1969

[4] T. M. Shakerley, C. J. Brown, "Elastic buckling of plates with eccentrically positioned rectangular perforations", International Journal of Mechanical Sciences, Vol. 38, No. 8-9, pp.825-38, 1996

[5] A. K. Soh, , L. C. Bian, J. Chakrabarty, "Elastic/Plastic Buckling of a Composite Flat Plate Subjected to Uniform Edge Compression", ThinWalled Structures, Vol. 38, No. 3, pp. 247-265, 2000

[6] X. Wang, X. Wang, X. Shi, "Accurate buckling loads of thin rectangular plates under parabolic edge compressions by the differential quadrature method", International Journal of Mechanical Sciences, Vol. 49, No. 4, pp. 447-453, 2007

[7] X. Wang, Differential Quadrature and Differential Quadrature Based Element Methods Theory and Applications, Elsevier Inc., United States, 2015

[8] A. Gheitasi, M. M. Alinia, "Slenderness classification of Unstiffened Metal Plates under Shear Loading", Thin-Walled Structures. Vol. 48, No. 7, pp. 508-518, 2010

[9] B. Torstenfelt, Finite Elements - From the early beginning to the very end, LiU-Tryck, Linkoping, 2007

[10] K. Hibbitt, ABAQUS/Standard Theory Manual, Sorenson Inc, 2016

[11] Euro code 3 EN 1993-1-5, "Design of Steel Structures. Part 1.5 Plated Structural Elements", 2006

[12] D. Beg, U. Kuhlmann, L. Davaine, B. Braun, “Design of Plated Structures, ECCS Euro code Design Manuals, Ernst \& Sohn, Berlin, 2010 